\title{
BALANÇO SOCIAL: ANÁLISE DOS MODELOS PRATICADOS ATUALMENTE E INDÍCIOS DE PADRONIZAÇÃO EM EMPRESAS QUE FAZEM PARTE DO ÍNDICE DE SUSTENTABILIDADE EMPRESARIAL
}

\author{
SOCIAL BALANCE: ANALYSIS OF CURRENTLY PRACTICED MODELS AND \\ STANDARDIZATION INDEXES IN COMPANIES THAT ARE PART OF THE \\ BUSINESS SUSTAINABILITY INDEX
}

\begin{abstract}
Letícia Garrido de Aguiar $^{1}$
Tecnóloga em Gestão Financeira pela Faculdade de Tecnologia de Osasco aguiar.leticia@gmail.com

Taís Cristina de Oliveira

Tecnóloga em Gestão Financeira pela Faculdade de Tecnologia de Osasco) taiscris@gmail.com
\end{abstract}

\section{RESUMO}

O objetivo deste estudo é fazer análise dos Balanços Sociais publicados pelas empresas no modelo feito pelo Instituto Brasileiro de Análise Sociais e Econômicas (Ibase), que fazem parte da carteira do Índice de Sustentabilidade Empresarial (ISE) e verificar se essas empresas publicaram informações semelhantes, relevantes e se houve uma padronização. A metodologia utilizada neste trabalho foi o método quantitativo e as técnicas utilizadas foram a amostragem não probabilista e a tabulação. A amostra é composta por 14 empresas que publicaram, em 2014, os Balanços Sociais no modelo nacional Ibase, sendo que todas as informações de todos os Balanços Sociais foram analisadas. Foi estabelecido o score de corte de $64 \%$ com base em valores absolutos, sendo que este valor pode ser considerado significativo, pois a próxima porcentagem é de $29 \%$. Como não há um meio termo entre estes valores, as informações relevantes e que estariam em um possível padrão seriam as publicadas por $64 \%$ ou mais das empresas. Foram encontradas informações semelhantes e relevantes entre as empresas e por isso, evidenciaram um possível padrão.

Palavras-chaves: Balanço Social; Sustentabilidade Empresarial; Índice de Sustentabilidade Empresarial, Relato Integrado.

\footnotetext{
${ }^{1}$ Autor para correspondência: Faculdade de Tecnologia do Estado de São Paulo, Rua Pedro Rissato, 30, Vila dos

Remédios, Osasco - SP, Brasil - CEP 06296-220.
}

Revista ENIAC Pesquisa, Guarulhos (SP), V.7, n.1, jan.- jun. 2018. 


\section{ABSTRACT}

The objective of this study is to analyze the Social Reports published by companies in the Ibase model wich are part of the Corporate Sustainability Index (ISE), to verify if those companies have published similar, relevant information and if there was a pattern. The methodology used in this study was the quantitative method and the techniques used were the not probabilistic sample and tabulation. The sample is composed by 14 companies that published, in 2014, the Social Balance in the national Ibase model. All information of all Social Reports were analyzed. The cut score of $64 \%$ was stablished based on absolute values, and the value is significant, once the next percentage is 29\%. And how is not an half term between these values, the relevant information and would be in a possible pattern would be the information published by $64 \%$ or more of the companies. Similar and relevant information between companies, and, therefore, could show a possible pattern.

key-words: Social Reporting; Corporate Sustainability; Corporate Sustainability Index, Integrated Reporting.

\section{INTRODUÇÃO}

O Balanço Social é uma forma de divulgar as informações empresariais para a sociedade, segundo Hanashiro, Teixeira \& Zaccarelli (2008), além de informar a sociedade, deve comprovar que os benefícios são superiores aos custos e que ele consegue valorizar ainda mais a economia e a sociedade, criando processos que não maltratem o meio ambiente, complementa Costa (2012).

O Balanço Social evidencia a sustentabilidade, a governança corporativa e a responsabilidade social das empresas, buscando demonstrar como está inserida na sociedade e sua contribuição a ela. Estes fatos motivaram a elaboração desta pesquisa, que identificou informações pertinentes aos Balanços Sociais publicados pelas empresas que fazem parte da carteira do Índice de Sustentabilidade Empresarial (ISE).

O contexto da pesquisa foi o Balanço Social e os demais temas abordados nos capítulos, e o foco da análise foram as informações de maior incidência. A base teórica advém da área da Contabilidade Social, especificamente, à área social e ambiental.

A Lei 11.638/07, conforme Brasil (2007), não cita obrigatoriedade para as informações de natureza social e ambiental, apenas para demonstrações financeiras.

Revista ENIAC Pesquisa, Guarulhos (SP), V.7, n.1, jan.- jun. 2018. 
Conforme Daher (2006) e Santos (2015), mesmo as empresas não sendo obrigadas a fazê-lo, as que optarem devem adotar as Normas Brasileiras de Contabilidade Técnica ${ }^{\circ} 15$ (NBC T 15), segundo Conselho Federal de Contabilidade - CFC (2004).

Há modelos de Balanço Social conhecidos, segundo Tinoco (2010), os modelos nacionais são Ibase e Ethos e o internacional é Global Reporting Initiative (GRI). As empresas escolhidas para elaboração deste trabalho foram apenas as que optaram pelos modelos nacionais, pois de acordo com Tinoco (2010), o GRI é um relatório de sustentabilidade, considerado como um similar ao Balanço Social. Os Balanços Sociais encontrados no Índice de Sustentabilidade Empresarial foram os modelos GRI e Ibase, por este motivo, foi utilizado o modelo nacional Ibase.

Segundo Cunha \& Ribeiro (2004), o Balanço Social é importante para tornar a relação da empresa com a sociedade mais transparente. Tinoco (2010) complementa que o Balanço Social traz uma gestão mais transparente, associando o tema a Governança Corporativa.

\section{REFERENCIAL TEÓRICO}

\subsection{BALANÇO SOCIAL}

Conforme santos \& santos (2014), o Balanço Social tem sido uma maneira de comunicação de fácil entendimento que demonstra o comprometimento da empresa com o meio ambiente e o coletivo.

Conforme Zarpelon (2006), é um mecanismo formal em que as empresas publicam seu desempenho social. Ribeiro \& Lisboa (1999), no mesmo raciocínio, informa que esta maneira de divulgação deve deixar em evidência o motivo de sua existência, conforme o Projeto de Lei 3.116/97 “O balanço social é um instrumento de informação”, ou Kroetz (2000, p. 55), em que é uma prestação de contas à sociedade. Pinto \& Ribeiro (2005), cita que esta demonstração tem o objetivo de publicar a responsabilidade social das empresas.

Kroetz (2000), com uma visão mais ampla, afirma que o balanço social "é uma ferramenta gerencial que reúne dados quantitativos e qualitativos sobre políticas administrativas e as relações entidade e ambiente", o que vai além de ser uma demonstração a sociedade, chegando a afirmar que é instrumento de auxílio para a tomada de decisões, no mesmo caminho Gonçalves (1980), afirma que o Balanço Social oferecerá aos dirigentes das

Revista ENIAC Pesquisa, Guarulhos (SP), V.7, n.1, jan.- jun. 2018. 
empresas informações no âmbito social que serão essenciais para tomadas de decisão (tornando-as mais sociais).

De acordo com CFC (2004), a NBC T 15, que trata das informações de natureza social e ambiental, o Balanço Social tem mostrado a participação e a responsabilidade social da empresa, Santos (2015), completa que foi um documento para as empresas demonstrarem projetos e ações sociais, impactos, relações ambientais e as relações entre o público interno e externo.

Conforme Costa (2012), o Balanço Social tem como objetivo mostrar o efeito da relação da empresa com o meio ambiente, dando uma ênfase maior em alguns aspectos, como: os recursos humanos e ambientais e as contribuições para a economia, sociedade e para a parte social.

Santos (2009), afirma que algumas empresas ao fazer compras têm analisado o Balanço Social do seu fornecedor, analisando se tem projetos ou alguma ação voltada para o benefício da sociedade e do desenvolvimento sustentável.

Segundo Santos (2003), “o Balanço Social é estudado em quatro vertentes” são elas balanço Ambiental, balanço de Recursos Humanos, Demonstração do Valor Adicionado e Benefícios e Contribuições a Sociedade em Geral, completa Tinoco \& Kraemer (2004), que estas quatro devem andar juntas, como já acontece em outros países. Tinoco (2010), divide de acordo com a norma e acrescenta, além destas, as atividades exercidas pelas entidades, que identificam os produtos/serviços que geram valor à empresa. Conforme CFC (2004), a NBC T 15 as dividem em: "a geração e distribuição de riqueza, os recursos humanos, a interação da entidade com o ambiente externo, e a interação com o meio ambiente".

\subsection{BALANÇO SOCIAL NO MUNDO}

Até 1950, de acordo com Tenório (2006), as empresas estavam tentando aumentar seus lucros. A responsabilidade social não era estimulada por parte do governo. E as empresas condenavam suas práticas. A industrialização causou uma qualidade de vida deteriorada, inclusive aos trabalhadores, além dos problemas ambientais. Os problemas trabalhistas eram devido às árduas jornadas de trabalho.

A partir dos anos 70, segundo Tenório (2006), o tema entra em evidência. Principalmente nos Estados Unidos e na Europa, conforme Tinoco (2010), os cidadãos

Revista ENIAC Pesquisa, Guarulhos (SP), V.7, n.1, jan.- jun. 2018. 
reivindicaram por responsabilidade ambiental e social. Sendo que em 1977, foi implementada na França a Lei $n^{\circ} 77.769 / 77$ onde obriga a elaboração e a publicação do Balanço Social.

De acordo com Tinoco (2010), devido ao capitalismo foi nos Estados Unidos da América que começaram os debates sobre responsabilidade social.

Nos países com maior desenvolvimento, segundo Tinoco (2010), as empresas utilizam o Balanço Social como instrumento de gestão, além de instrumento de informação. Sendo que o mesmo documento possui indicadores que atendem tanto acionistas quanto os colaboradores.

Conforme Santos (2015), o International Integrated Reporting Council (IIRC) devem criar um modelo global de Relato Integrado. Evidenciando que o mesmo é uma tendência mundial da importância de trazer as demonstrações financeiras e não financeiras em um mesmo documento. Outro autor que corrobora sobre o Relato Integrado é Carvalho \& Kassai (2013), que informa que desde 2010 está sendo discutido o assunto e que é compatível ao GRI.

\subsection{BALANÇO SOCIAL NO BRASIL}

Segundo Cunha \& Ribeiro (2004) e Tinoco (2001), o assunto sobre comportamento ético e responsabilidade social empresarial surgiu no Brasil nos anos 60 com a criação da Associação dos Dirigentes Cristãos de Empresas (ADCE).

De acordo com Tinoco (2001), a ADCE promoveu o segundo Encontro Nacional de Dirigentes de empresas, tendo como assunto principal o Balanço Social da Empresa.

Segundo Kroetz (2000), em meados de 1976 foi apresentado um Balanço Social adequado ao Brasil.

Foi nos anos 80, de acordo com Santos \& Santos (2014), que apareceram os primeiros Balanços Sociais, embora viesse sendo discutida desde 70 e se consolidaria apenas em 90.

De acordo com Cunha \& Ribeiro (2004), a discussão sobre adotar a publicação do Balanço Social no Brasil surgiu com o artigo do Herbert de Souza, conhecido como Betinho. Este fato teria sido o marco zero sobre a discussão de Balanço Social no país.

Segundo Daher (2006), um modelo de Balanço Social foi desenvolvido em 1997 pelo Instituto Brasileiro de Análise Sociais e Econômicas (Ibase), tendo à frente o sociólogo

Revista ENIAC Pesquisa, Guarulhos (SP), V.7, n.1, jan.- jun. 2018. 
Betinho, que foi apoiado também por empresários da Comissão de Valores Mobiliários (CVM) e pelo jornal Gazeta Mercantil.

Conforme Kroetz (2000), houve o Projeto de Lei $\mathrm{n}^{\text {o }} 3.116 / 97$,e existia no Senado Federal outro Projeto de Lei $\mathrm{n}^{\circ} 117 / 96$, a respeito da obrigatoriedade de publicação do Balanço Social.

Em 2001, o número de empresas brasileiras que publicavam o Balanço Social ainda era reduzido, pois apenas aproximadamente 70 empresas o publicavam. Esse cenário é devido ao fato de não ser obrigatório e das empresas se preocuparem com os custos adicionais, segundo Tinoco (2001).

A tendência, segundo Santos (2015), é o Relato Integrado que evidência a importância das informações financeiras e não financeiras. O Brasil criou, desde 2012, uma Comissão que acompanha os Relatos Integrados, porém é um processo em desenvolvimento.

\subsection{INDICADORES E MODELOS}

Há modelos conhecidos, segundo Tinoco (2010), ligados à elaboração e divulgação do Balanço Social. Os modelos nacionais são Ibase e Ethos e o internacional é o GRI. TINOCO \& KRAEMER (2004, p. 282) complementa que a GRI não dispõe de modelo de Balanço Social.

Conforme Marcondes \& Bacarji (2010), diversos fatos, tais como a Guerra do Vietnã, o apartheid na África do Sul e o acidente em Chernobyl, criaram um ambiente favorável para que a Bolsa de Valores de São Paulo, em parceria com a Fundação Getúlio Vargas (FGV), criasse em 2005 um índice, o Índice de Sustentabilidade Empresarial (ISE). Este índice analisa fatores éticos, sociais e ambientais trazendo mais transparência. Atualmente, um dos principais indicadores. O ISE, de acordo com Tinoco (2010), confirmou a sustentabilidade no contexto do Brasil.

Tinoco (2010), insere indicadores em cada dimensão do Balanço Social, sendo que os indicadores seriam a base para criação da estrutura, e alguns destes indicadores traduzem a situação econômica. Para reunir informações dos indicadores e os tornar transparentes, requer a colaboração de diversos departamentos. Há diversos indicadores, classificados quantitativamente e qualitativamente.

Revista ENIAC Pesquisa, Guarulhos (SP), V.7, n.1, jan.- jun. 2018. 
Conforme Hanashiro, Teixeira \& Zaccarelli (2008), no modelo Ibase há os indicadores "sociais internos e externos, ambientais, do corpo funcional e informações relevantes quanto ao exercício da cidadania empresarial".

Segundo Tinoco (2010), há diferentes indicadores para diferentes segmentos de empresas, portanto, há empresas que será necessário apresentar indicadores de ecoeficiência e em outras isso seria inexistente.

Segundo Santos \& Santos (2014) no Brasil são utilizados três modelos de Balanço Social. Estes modelos são distintos podendo causar problemas na mensuração de suas informações.

De acordo com Marcondes \& Bacarji (2010), o primeiro índice a ser criado, em 1999, foi o Dow Jones Sustainability Indexes (DJSI) em Nova Iorque. O segundo índice surgiu em b2001, o Índice de Sustentabilidade da Bolsa de Londres, Financial Times Stock Exchange for Good (FTSE4Good), o terceiro aconteceu em 2003, o Johannesburg Stock Exchange (JSE) e o quarto foi o ISE. O ISE foi criado por um processo participativo composto por vários executivos do mercado de ações e especialistas, empresas e instituições, gerando credibilidade. Atingindo um público de investidor preocupado com valores socioambientais.

\section{METODOLOGIA}

A metodologia utilizada neste trabalho, conforme Gonsalves (2011) foi baseada na pesquisa de levantamento de dados, que foram as informações encontradas nos Balanços Sociais e no método quantitativo, sendo que a explicação foi dada por meio de testes de hipóteses a partir das informações coletadas. É uma pesquisa objetiva, pois trabalha com hipóteses. É bibliográfica, quantitativa e qualitativa. As técnicas utilizadas foram a amostragem não probabilista, pois os dados não são escolhidos aleatoriamente e a tabulação, segundo Lakatos \& Marconi (2011).

As informações foram coletadas a partir dos Balanços Sociais publicados por empresas que fazem parte da Carteira do ISE disponível no dia 22/09/2015, segundo o site da BM\&FBovespa (2015), o universo da pesquisa é composto por 40 empresas.

Da carteira do ISE as empresas que publicaram Balanço Social pelo modelo Ibase e que fizeram parte da amostra da pesquisa foram apenas catorze: AES Tietê, Eletropaulo, Bradesco, Cemig, Copel, CPFL Energia, Ecorodovias, EDP - Energias do Brasil, Eletrobrás,

Revista ENIAC Pesquisa, Guarulhos (SP), V.7, n.1, jan.- jun. 2018. 
Embraer, Light S/A, Sabesp, Tim Participações S/A, Tractebel. As demais publicaram apenas no modelo GRI, não correspondendo a todas as informações solicitadas para se caracterizar Balanço Social.

As informações foram analisadas, após a coleta dos dados e tabulação. De acordo com a tabela de frequência foi determinado que as informações foram consideradas como provável padrão a partir de percentil sessenta e quatro (64\%). Este score de corte foi estabelecido com base em valores absolutos, sendo que, o valor de 64\% é significativo, uma vez que a próxima porcentagem é d/e 29\%, sendo discrepante, e percebido a dispersão entre as informações. Analisando qualitativamente não há um meio termo entre estes valores, conforme é demostrado no gráfico 1, o degrau entre os dados nos mostra esta evidência.

Gráfico 1: Porcentagem de informações geral

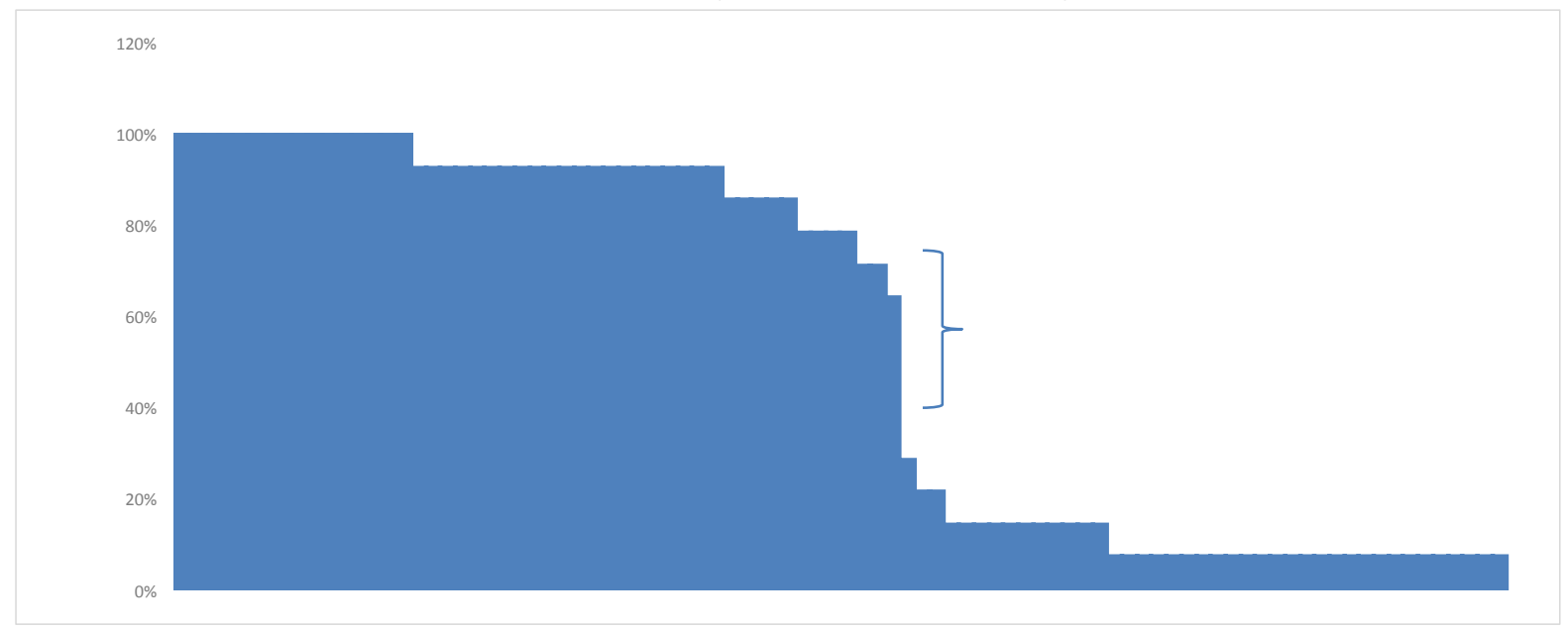

Fonte: Dados da pesquisa, 2017.

\section{ANÁLISE E DISCUSSÃO}

Analisando os Balanços Sociais, foram tabuladas as informações de acordo com a porcentagem de publicação. Pode-se verificar as porcentagens das informações fornecidas pelas empresas descritas, no gráfico 2:

Revista ENIAC Pesquisa, Guarulhos (SP), V.7, n.1, jan.- jun. 2018. 


\section{Gráfico 2: Porcentagem de informações}

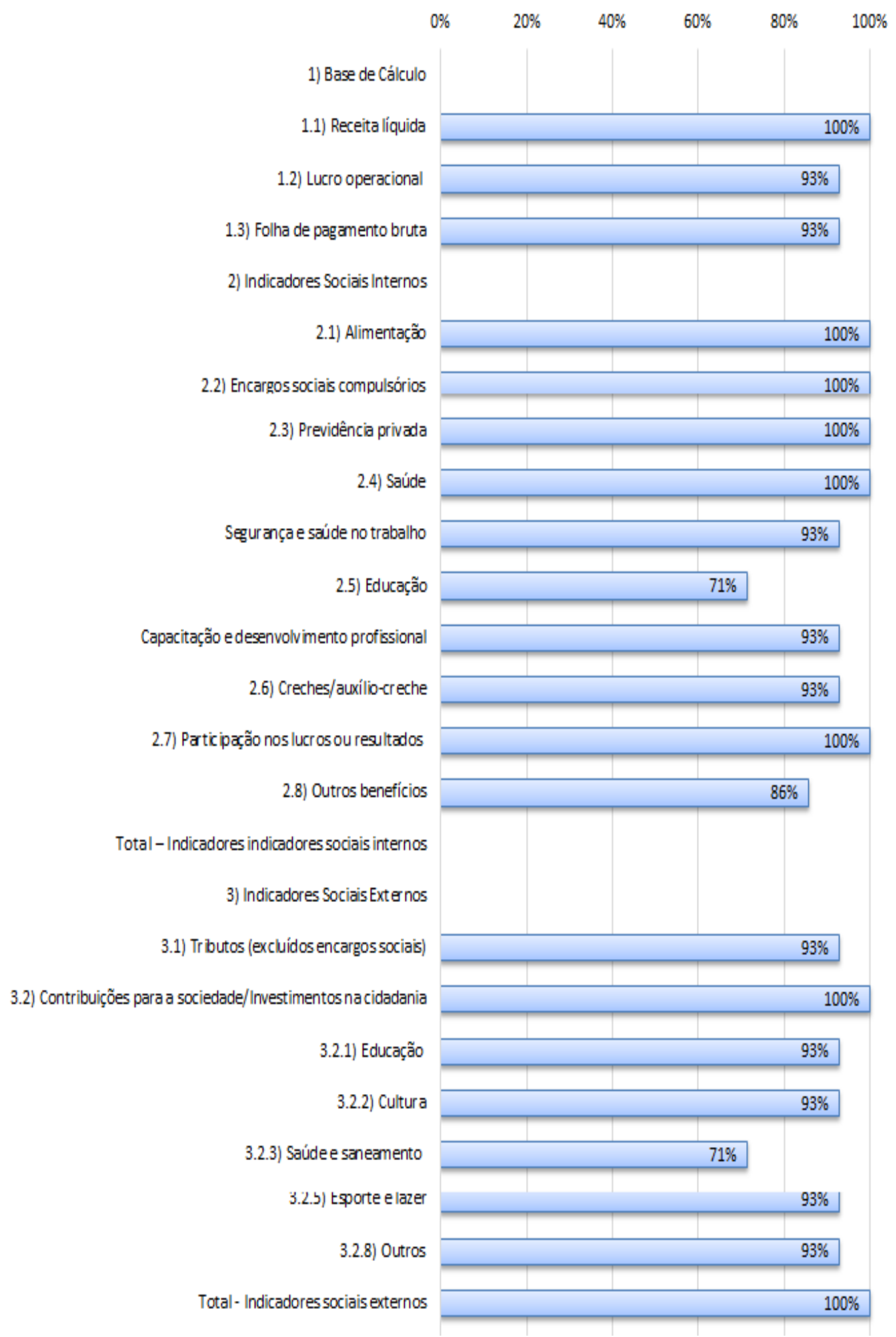

Revista ENIAC Pesquisa, Guarulhos (SP), V.7, n.1, jan.- jun. 2018. 


\section{Gráfico 2: Porcentagem por informações (continuação)}

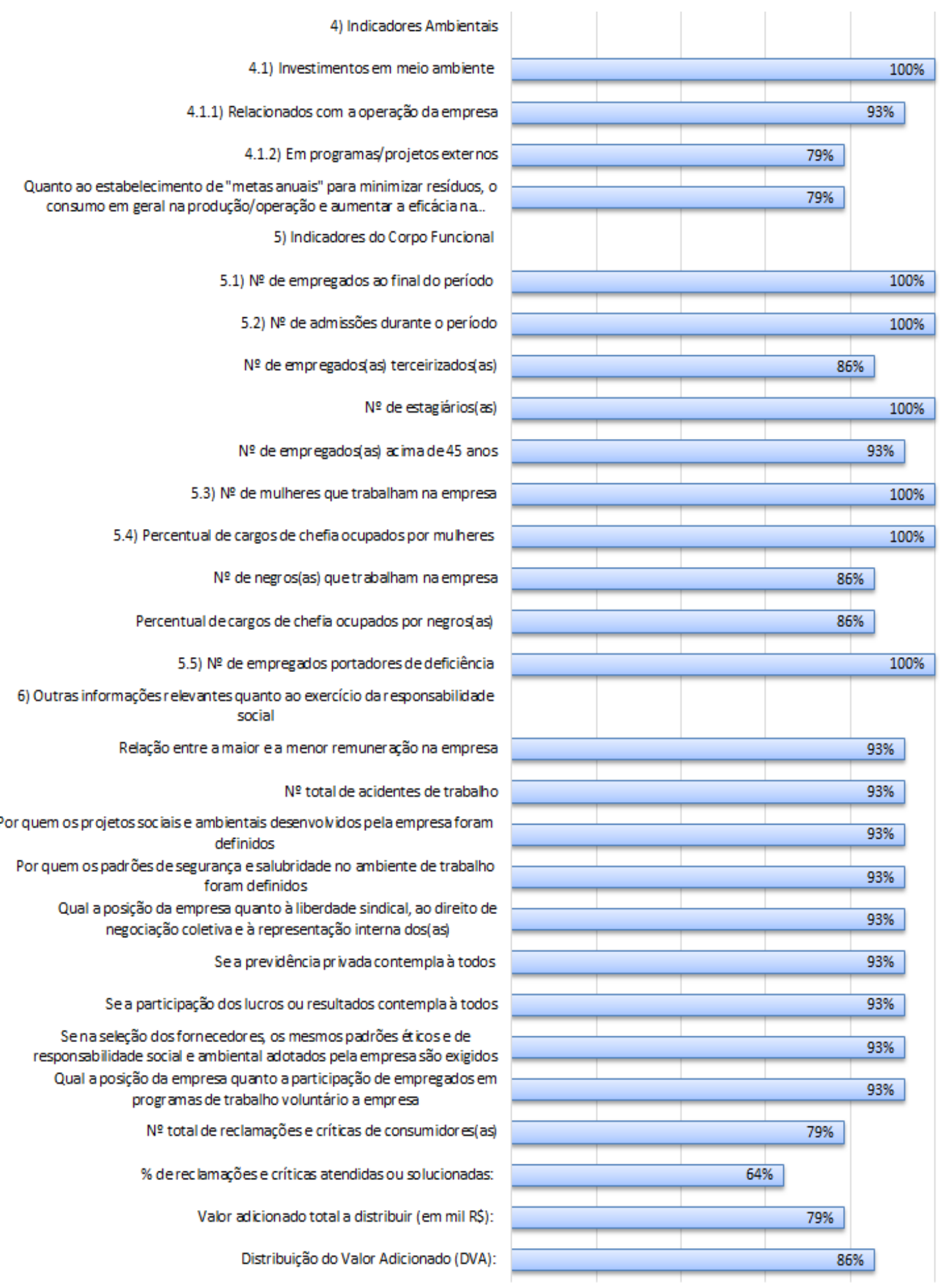

Fonte: Dados da pesquisa, 2017.

Revista ENIAC Pesquisa, Guarulhos (SP), V.7, n.1, jan.- jun. 2018. 
A porcentagem por empresa foi obtida da porcentagem de informações fornecidas, que estariam em um provável padrão (com informações relevantes acima de 64\%), dividida pelas empresas analisadas.

Gráfico 3: Porcentagem por empresa

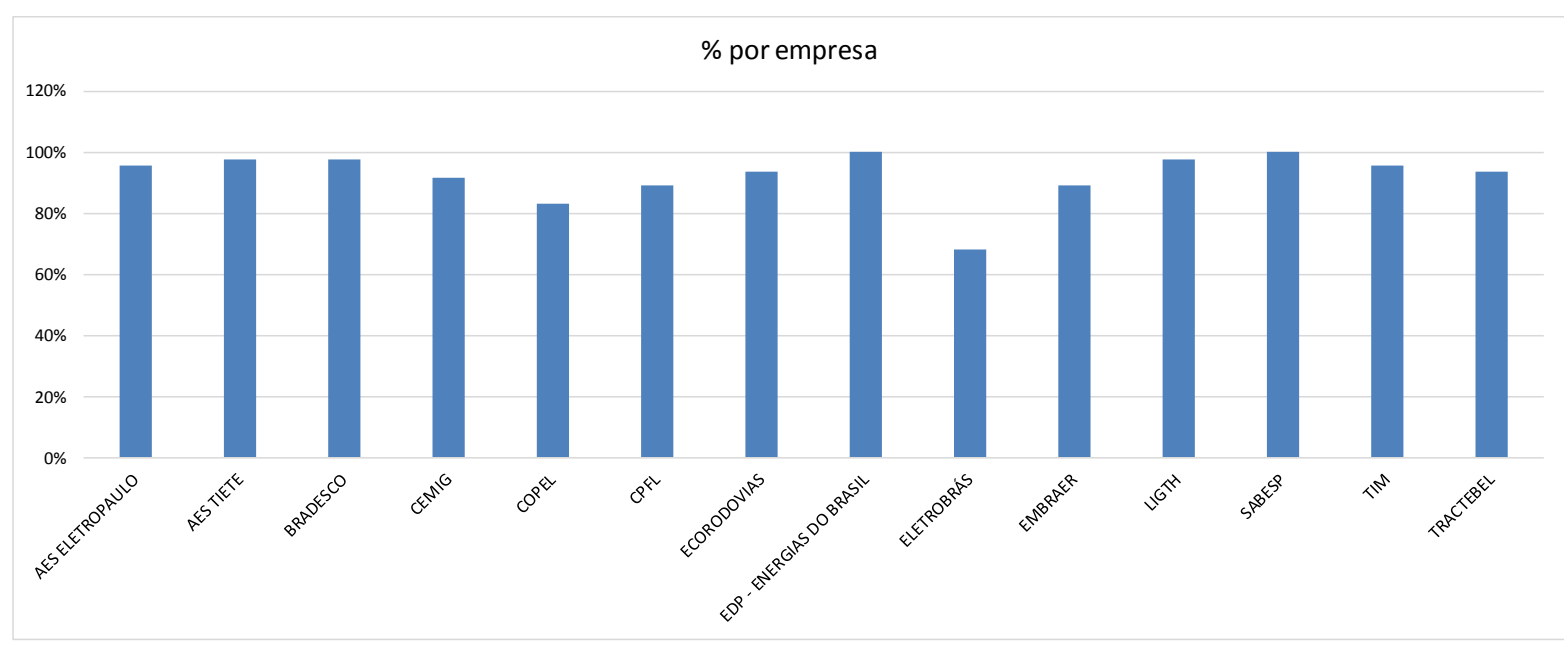

Fonte: Dados da pesquisa, 2017.

No gráfico 3, pode-se verificar que somente a EDP - Energias do Brasil e a Sabesp forneceram $100 \%$ das informações percebidas em um provável padrão, com informações do antigo e do novo modelo de Balanço Social. As empresas AES Tietê, Bradesco e Light forneceram $98 \%$ das informações. As empresas AES Eletropaulo e Tim forneceram 96\% das informações. A empresa Ecorodovias e Tractebel forneceram 94\% das informações. A empresa Cemig forneceu 91\% das informações. As empresas CPFL e Embraer forneceram 89\% das informações. A empresa Copel forneceu $83 \%$ das informações. E a empresa Eletrobrás forneceu $68 \%$ das informações.

\section{CONSIDERAÇÕES FINAIS}

O Balanço Social é uma maneira de demonstrar a responsabilidade social e a preocupação da empresa com o meio ambiente. O Balanço Social não é obrigatório e não possui um padrão específico, porém é uma das ferramentas de divulgação das informações

Revista ENIAC Pesquisa, Guarulhos (SP), V.7, n.1, jan.- jun. 2018. 
empresariais para as partes interessadas, além de especificar como essas informações são distribuídas e quais são os benefícios trazidos para a sociedade.

O objetivo era analisar as informações publicadas pelo modelo Ibase nos Balanços Sociais e, através da análise, pode-se perceber indícios de um provável padrão. Os objetivos específicos foram atingidos, identificados os modelos de Balanço Social; verificado que os modelos são distintos, não havendo possibilidade de comparação entre os modelos Ibase e GRI, identificados na carteira do ISE; entre as informações publicadas pelo modelo Ibase foi reconhecido um provável padrão; sendo que, foi analisado através da associação entre os modelos praticados nas empresas que publicam por meio do modelo Ibase.

Após análise dos Balanços Sociais publicados pelas empresas no modelo Ibase que fazem parte da carteira do Índice de Sustentabilidade Empresarial (ISE) foi verificado que essas empresas publicam informações semelhantes e relevantes, identificando-se uma possível padronização, confirmando a hipótese de que haveria um provável padrão. Foi estabelecido que as informações relevantes e que estariam em um possível padrão são as publicadas por $64 \%$ ou mais das empresas.

Este trabalho apresentou como limitação o tamanho da amostra, foi utilizado o modelo Ibase devido ao GRI ser um relatório de sustentabilidade, considerado como um similar ao Balanço Social. Porém, verificando a carteira do ISE, a maioria das empresas optam por publicá-lo.

A importância do trabalho está nas demonstrações das responsabilidades socioambientais das empresas e os resultados trazem a situação apenas da amostra estudada, podendo ser desenvolvidas outras pesquisas com critérios mais amplos.

Como considerações futuras, devido ao grau de importância, deve-se citar o modelo global criado, denominado Relato Integrado, que é uma tendência. Embora não seja um modelo de Balanço Social, é uma evolução das demonstrações financeiras e não financeiras em um documento único.

\section{REFERÊNCIAS}

AES ELETROPAUlO. Quem somos. AES Eletropaulo, 2016. Disponivel em: $<$ https://www.aeseletropaulo.com.br/sobre-a-aes-eletropaulo/quem-somos/conteudo/aeseletorpaulo>. Acesso em: 01 de março de 2016.

Revista ENIAC Pesquisa, Guarulhos (SP), V.7, n.1, jan.- jun. 2018. 
Quem somos. AES Tiete, 2015. Disponivel em: <http://www.aestiete.com.br/empresa/Paginas/quem-somos.aspx\#conteudo>. Acesso em: 02 de março de 2016.

BMF\&BOVESPA. Empresas listadas. BMF\&Bovespa, 2016. Disponivel em: $<$ http://www.bmfbovespa.com.br/cias-listadas/empresaslistadas/ResumoEmpresaPrincipal.aspx ?codigoCvm=18660\&idioma=pt-br $>$. Acesso em: 01 de março de 2016.

BRADESCO. $\quad$ Sobre, $2016 . \quad$ Disponivel <http://www.bradesco.com.br/html/classic/sobre/index.shtm>. Acesso em: 02 de março de 2016.

BRASIL. Lei $\mathbf{n}^{\mathbf{0} 11.638}$, de 28 dezembro 2007. Disponivel em: <Disponível em www.planalto.gov.br>.

CARVALHO, L. N.; KASSAI, J. R. Relato integrado. in FONTES FILHO, J. R.; LEAL, R. P. C. (org.). O futuro da governança corporativa: desafios e novas fronteiras. São Paulo: Saint Paul Editora, 2013.

CEMIG. Quem somos. Cemig, 2016. Disponivel em: <http://www.cemig.com.br/ptbr/a_cemig/quem_somos/Paginas/default.aspx>. Acesso em: 02 de março de 2016.

CFC - CONSELHO FEDERAL DE CONTABILIDADE. Resolução n 1.003/2004. Norma Brasileira de Contabilidade NBC T 15, de 19 agosto 2004. Disponivel em: <Disponível em www.jus.gov.br>.

COPEL. A Copel. Copel, 2011. Disponivel em: <http://www.copel.com/hpcopel/acopel/atuacao.jsp>. Acesso em: 02 de março de 2016.

COSTA, C. A. G. D. Contabilidade ambiental: mensuração, evidenciação e transparência. São Paulo: Atlas, 2012.

CPFL. Quem somos. CPFL, 2016. Disponivel em: <http://www.cpfl.com.br/institucional/quem-somos/Paginas/default.aspx >. Acesso em: 03 de março de 2016.

CUNHA, J. V. A. D.; RIBEIRO, M. D. S. Evolução e diagnóstico atual do balanço social. IV Congresso USP de controladoria e contabilidade, São Paulo, 2004. São Paulo, p. 116, 2004.

DAHER, W. D. M. Responsabilidade social e corporativa: geração de valor reputacional nas organizações internacionalizadas. São Paulo: Saint Paul Editora, 2006.

ECORODOVIAS. Histórico. Ecorodovias, 2016. Disponivel em: <http://www.ecorodovias.com.br/A-Companhia/Histórico>. Acesso em: 03 de março de 2016.

Revista ENIAC Pesquisa, Guarulhos (SP), V.7, n.1, jan.- jun. 2018. 
EDP. Conheça EDP. EDP, 2011. Disponivel em: <http://www.edp.com.br/conhecaedp/perfil_de_negocios/Paginas/default.aspx>. Acesso em: 03 de março de 2016.

ELETROBRÁS. Home. Eletrobrás, 2010. Disponivel em: $<$ http://www.eletrobras.com/elb/main.asp?Team=

EMBRAER. Conheça a Embraer. Embraer, 2011. Disponivel em: < goo.gl/vH3C4z>. Acesso em: 04 de março de 2016.

ENGIE. A companhia. Tractebel Energia, 2010. Disponivel em: <http://www.tractebelenergia.com.br/wps/portal/internet/a-companhia>. Acesso em: 05 de março de 2016.

GONÇALVES, E. L. (org.). Balanço social da empresa na América latina. São Paulo: Livraria Pioneira Editora, 1980.

GONSALVES, E. P. Conversas sobre iniciação à pesquisa científica. Campinas: Alínea, 2011.

HANASHIRO, D. M. M.; TEIXEIRA, M. L. M.; ZACCARELLI, L. M. Gestão do Fator Humano: Uma visão baseada em stakeholders. São Paulo: Saraiva, 2008.

HERRERA, G. M. D. Academic trends in the study of corporate social responsability and development issues in Latin America, 2000-2010. Cuadernos de Administración, Cali, Colombia. Universidad del Valle: vol. 29, núm. 49, p.85-94, enero-junio de 2013.

IIRC - INTERNATIONAL INTEGRATED REPORTING COUNCIL. International Integrated Reporting Framework. Integrated Reporting, 2014. Disponivel em: $<\mathrm{http}$ ://integratedreporting.org/resource/international-ir-framework/>. Acesso em: $07 \mathrm{de}$ agosto de 2015.

Disponivel

Comissão Brasileira. Relato Integrado Brasil, 26 de novembro de 2015. $<$ http://www.relatointegradobrasil.com.br/conteudo_pt.asp?idioma $=0 \&$ conta $=28 \&$ tipo $=55$ 215>. Acesso em: 13 de abril de 2016.

KROETZ, C. E. S. Balanço social: teoria e prática. São Paulo: Atlas, 2000.

LIGHT. Quem somos. Light, 2012. Disponivel em: <http://www.light.com.br/grupolight/Quem-Somos/default.aspx>. Acesso em: 04 de março de 2016.

LISBOA, L. P.; RIBEIRO, M. D. S. Balanço social: instrumento de divulgação da interação da empresa com a sociedade. Revista brasileira de contabilidade, 1999. Brasília: CFC, ano $28, \mathrm{n}^{\circ} 115, \mathrm{jan} / \mathrm{fev}$, , 1999.

MARCONDES, A. W.; BACARJI, C. D. ISE: sustentabilidade no mercado de capitais. São Paulo: Report Ed, 2010.

Revista ENIAC Pesquisa, Guarulhos (SP), V.7, n.1, jan.- jun. 2018. 
MINGONE, R. S. Relatório Integrado informações social \& ambiental é informação financeira. Revista RI, p. 32-35, setembro de 2012.

NOVELINI, C. P.; KRAUTER, E. Uma análise dos balanços sociais de companhias listadas no índice de sustentabilidade empresarial. XVIII Congresso Brasileiro de Custos, Rio de Janeiro, 07 a 09 de novembro de 2011.

PANDOLFI, D.; GAZIR, A.; CORRÊA, L. O Brasil de betinho. Rio de Janeiro: Mórula Editorial, 2012.

PINTO, A. L.; RIBEIRO, M. D. S. Balanço social: avaliação de informações fornecidas por empresas industriais situadas no estado de Santa Catarina. Revista Contabilidade \& Finanças, 2005. São Paulo, n. 36, p. 21-34, set./dez. 2005.

SABESP. Institucional. Sabesp, 2016. Disponivel em: <http://site.sabesp.com.br/site/interna/Default.aspx?secaoId=505>. Acesso em: 04 de março de 2016.

SANTOS, A. D. Demonstração do valor adicionado: como elaborar e analisar a DVA. São Paulo: Atlas, 2003.

SANTOS, Fernando de Almeida. Ética empresarial: políticas de responsabilidade social em 5 dimensões: sustentabilidade, respeito à multicultura, apredizado contínuo, inovação e governança corporativa. São Paulo: Atlas, 2015.

SANTOS, Fernando de Almeida. Ética e responsabilidade social: uma prática cotidiana. in BARROS NETO, J. P. (org.). Administração de organizações complexas: liderando e simplificando a gestão para criar valor e maximizar resultados. Rio de Janeiro: Qualitymark, 2009.

SANTOS, Fernando de Almeida. Experiências corporativas em sustentabilidade e responsabilidade social. São Paulo: Baraúna, 2014.

SHLEIFER, A.; VISHNY, R. W. A survey of corporate governance. The Journal of finance, 1997. vol. 52, n² , (jun., 1997), p. 737-783.

SOUZA, H. Balanço Social nas empresas públicas. Folha de S. Paulo, São Paulo, 06 de maio de 1997. Disponivel em: 〈http://www1.folha.uol.com.br/fsp/opiniao/fz060509.htm>. Acesso em: 05 de agosto de 2015.

TENÓRIO, F. G. (org.). Responsabilidade social empresarial: teoria e prática. $2^{\mathrm{a}}$ ed. rev. e ampl. ed. Rio de Janeiro: Editora FGV, 2006.

TIM CELULAR. Perfil. Tim, 2010. Disponivel em: $<$ http://ri.tim.com.br/Show/Perfil?=xakgps50Y2n1v/QLLoqQJQ==>. Acesso em: 05 de março de 2016.

Revista ENIAC Pesquisa, Guarulhos (SP), V.7, n.1, jan.- jun. 2018. 
TINOCO, J. E. P. Balanço social: uma abordagem da transparência e da responsabilidade pública das organizações. São Paulo: Atlas, 2001.

Balanço social e o relatório da sustentabilidade. São Paulo: Atlas, 2010.

TINOCO, J. E. P.; KRAEMER, M. E. P. Contabilidade e gestão ambiental. São Paulo: Atlas, 2004.

ZARPELON, M. I. Gestão e responsabilidade social: NBR 16.001/SA 8.000: implantação e prática. Rio de Janeiro: Qualitymark, 2006.

Revista ENIAC Pesquisa, Guarulhos (SP), V.7, n.1, jan.- jun. 2018. 